composition, but also texture, determine the degree of resistance to all these factors. The qualities of metals required for chemical purposes may be improved by $(a)$ the elimination of impurities, $(b)$ adding other metals in such quantities as to produce substantially new alloys, or $(c)$ adding very small quantities of foreign elements which produce an effect great in proportion to their amount.

\section{Neolithic Camp in Sussex}

Discoveries which will have a bearing of no little importance on the future study of the neolithic age in Britain are reported from Whitehawk Camp, near Brighton. Mr. E. Cecil Curwen, acting on behalf of the Sussex Archæological Society, with the assistance of Miss Leslie Scott, who has worked at Maiden Castle, Dorchester, has held an archæological watching brief while the Corporation of Brighton has been engaged in constructing a road across the camp. Whitehawk Camp, which is scheduled under the Ancient Monuments Acts, is one of the largest and best surviving specimens of the neolithic camp of concentric interrupted ditches. In places, the original ramparts still stand seven feet high. The line of the road cuts the line of all four ditches on both sides of the camp, and these are now being cleared down to the bottom and the original chalk. According to a report in The Times of November 4, up to the present, the inner ditch has proved rich in neolithic pottery, also yielding great quantities of animal bones, flint flakes, saws, scrapers and a flint axe. Two small pits full of neolithic pottery and animal bones appear to be unconnected with the ditches. Another interesting discovery is a piece of chalk scored with a chess board pattern, similar to a device found on the wall of a pit shaft on Harrow Hill, near Cissbury. Several post-holes on the ramparts appear to have supported palisades, and a similar structure is indicated as forming a side wall to the entrance passage through the outer rampart. These are unique in British neolithic camps. The pottery, which is of modified Windmill Hill type and a type with whipped cord impressions, suggesting Peterborough ware (Neolithic $B)$, should prove an important addition to existing material.

\section{Etruscan Forgery in the British Museum}

MEMORIES of an ancient controversy are revived by the action of the Trustees of the British Museum in withdrawing from exhibition in the Department of Greek and Roman Antiquities at Bloomsbury the widely known "Cervetri Sarcophagus". The revived and extended interest in Etruscan antiquity, marked especially by the recent publication of Dr. D. RandallMacIver's researches in the history and affinities of Etruscan culture, is, no doubt, largely responsible for the removal of a piece of which the antiquity and authenticity can no longer be held to be a matter of question, in view of the more critical examination to which details of design, structure and style can now be submitted in the light of greatly extended knowledge. Doubt as to the genuine character of the sarcophagus, indeed, was raised very soon after its acquisition by the British Museum as part of the
Castellani collection in 1873 ; and it was pointed out in March of the following year that the inscription on its lid was derived in part from a gold brooch in the Louvre, while another inscription, which had been misread, was indicated later as another possible source. The spurious character of the inscription has been admitted even by some who were prepared to argue for the sarcophagus as a genuine ancient example of Etruscan art. Now, however, the recognition of anachronistic and incongruous details in form and design stamp it as a forgery beyond dispute. There can be little doubt that the story to which reference is made in The Times of November 2 embodies the truth which came out in the quarrel between the brothers Pennelli, of whom Enrico, employed at the Louvre, boasted that he had made the sarcophagus, while Pietro had sold it to Castellani, stating that he had excavated it at Cervetri. It is unfortunate that the inquiry demanded by Sir Charles Newton, keeper of the Department at the time, was not pressed home.

\section{The Realm of the Stars}

The Realm of the Stars, or Rise Hvezd, is the title of a monthly journal edited by Dr. Hubert Slouka and published by the Czechoslovak Astronomical Society, which now has more than a thousand members. One of the objects of the Society and its journal is to encourage a wider appreciation of astronomy among educated Slav peoples, and from the journal it is evident that Czechoslovak astronomers are familiar with modern progress and with the latest instruments in use elsewhere. In the last fow issues of the journal there are recent photographs showing the appearance of the moon's surface, some spectrographs taken in Czech observatories and a number of illustrated semi-popular contributions and reports. One issue is mainly devoted to the proceedings of the international astronomical meeting held in Paris during July. Czechoslovak astronomers have interested themselves in such subjects as sunspots, the atmospheres of planets, and celestial bombardment. In the annual report for last year it is stated that 11,797 people and 130 school groups visited the Stefánik Observatory, near Prague. The Society also has observatories and branches in several provincial centres, and noteworthy observations from these groups are reported in Rise Hvezd, but being in the Czech language they can appeal only to their own members and, in a limited degree, to colleagues in other Slav countries.

\section{Nature Protection in Poland}

A Census of the wild creatures in the famous Polish National Park of Bialowicza gives the present numbers as 4 wolves, 9 lynx, 3 otters, 5 martens, 4 foxes, 5 badgers, 82 wild boars, 29 stags, 72 roebucks and many hares (Quarterly Information Bulletin concerning the Protection of Nature in Poland, $5, \mathrm{II} ; 1$ 1935). In the Park, there now exist 17 European bison, including half-bred individuals, and in Poland as a whole there are 21 of pure breed, out of the 70 known to exist in the world. The State Council for the Protection of Nature in Poland has issued three 